\title{
CLOSED LINEAR RELATIONS AND THEIR REGULAR POINTS
}

\author{
J.-Ph. Labrousse, A. Sandovici, H.S.V. De Snoo And H. Winkler
}

Abstract. For a closed linear relation $A$ in a Hilbert space $\mathfrak{H}$ the notions of resolvent set and set of points of regular type are extended to the set of regular points. Such points are defined in terms of quasi-Fredholm relations of degree 0 . The set of regular points is open and for $\lambda \in \mathbb{C}$ in this set the spaces $\operatorname{ker}(A-\lambda)$ and $\operatorname{ran}(A-\lambda)$ are continuous in the gap metric. Several characterizations of regular points are presented, in terms of the gap metric between corresponding null spaces, and in terms of generalized resolvents of the linear relation $A$.

Mathematics subject classification (2010): Primary 47A57, 47B25; Secondary 47A55, 47B65.

Keywords and phrases: Quasi-Fredholm relation, ascent, descent, generalized resolvent, gap metric, range space.

\section{REFERENCES}

[1] N. I. Achieser And I. M. Glasmann, Theorie der linearen Operatoren im Hilbert-Raum, 8th edition, Akademie-Verlag, Berlin, 1981.

[2] F. DeUTsCH, The angle between subspaces of a Hilbert space, in S. P. Singh (editor) Approximation Theory, Wavelets and Applications, Kluwer Academic Publishers, 1995, 107-130.

[3] J. DiXMIER, Études sur les varietés et les opérateurs de Julia avec quelques applications, Bull. Soc. Math. France 77 (1949), 11-101.

[4] K. FRIEDRICHS, On certain inequalities and characteristic value problems for analytic functions and for functions of two variables, Trans. Amer. Math. Soc. 41 (1937), 321-364.

[5] S. GoldBerg, Unbounded linear operators, Mc Graw Hill, New York, 1966.

[6] I. C. Gohberg AND M. G. KREǏN, Introduction to the theory of linear non-selfadjoint operators, Transl. Math. Monographs, Vol. 18, Amer. Math. Soc., 1969.

[7] S. Hassi, H. S. V. De Snoo, and F. H. Szafraniec, Componentwise and canonical decompositions of linear relations, Dissertationes Mathematicae, 465, 2009 (59 pages).

[8] T. Kato, Perturbation theory for linear operators, Springer-Verlag, Berlin, 1980.

[9] M. G. KreĬn, M. A. Krasnoselskil̆, And D. P. Milman, On the defect numbers of linear operators in a Banach space and on some geometric questions, Sb. Trud. Inst. Mat. Akad. Nauk Ukr. SSR 11 (1948), 97-112.

[10] J.-PH. LABRousse, Les opérateurs quasi Fredholm: une généralisation des opérateurs semi Fredholm, Rend. Circ. Mat. Palermo 29 (1980), 161-258.

[11] J.-Ph. Labrousse, A. Sandovici, H. S. V. De Snoo, And H. Winkler, The Kato decomposition of quasi-Fredholm relations, Operators and Matrices 4 (2010), 1-51.

[12] V. E. Lyantse, Some properties of idempotent operators, Teor. i Prik1. Mat. L'vov 1 (1959), 16-22 (Russian).

[13] D. C. SAlmon, Mathematical aspects of computed tomography, Handwritten lecture notes, 19761977.

[14] A. Sandovici, H. S. V. De Snoo, And H. Winkler, Ascent, descent, nullity, and defect for linear relations in linear spaces, Lin. Alg. Appl. 423 (2007), 456-497.

[15] M. H. Stone, Linear transformations in Hilbert space and their applications to analysis, American Mathematical Society Colloquium Publications, 15, Providence, RI, 1932. 